Cruz Palmera, Roberto. Delitos instrumentales: Aspectos de politica legislativa. BdeF, Buenos Aires/Montevideo, 2020, 327 pp., ISBN 978-9915-650-03-6.

\author{
http://dx.doi.org/10.18543/ed-68(2)-2020pp393-395
}

Recientemente la editorial BdeF ha publicado el trabajo del profesor, Roberto Cruz Palmera, titulado «Delitos instrumentales: Aspectos de política legislativa», un trabajo oportuno y necesario para los estudiosos del derecho penal.

La publicación se corresponde con la tesis doctoral elaborada por el autor y dirigida por el profesor Pablo Sánchez-Ostiz, catedrático de Derecho Penal de la Universidad de Navarra, quien, conjuntamente, prologa el libro, donde señala que: «(...) La investigación se inició al constatar que habia una serie de delitos caracterizados por anticipar la intervención penal a fases preparatorias; más en concreto, que entre estos había algunos centrados en una serie de objetos orientados a la comisión de delitos: programas, maquinaria, objetos... Lo curioso era que la idea de aquel viejo -y constitucionalmente derogadodelito de tenencia de útiles para el robo (el antiguo art. 509 CP 1973) volvia a hacer aparición, ahora bajo nuevas pero semejantes figuras delictivas. El legislador ha dado muestras en los últimos años en su interés por tipificar cada vez más conductas preparatorias. Como muestra y epigono de tal afán, el delito de autoadiestramiento para actividades terroristas (...)» Sánchez-Ostiz adelanta uno de los méritos de este libro, precisando que "Roberto Cruz no se ha conformado con la crítica negativa, sino que se ha embarcado en la dificil pero apasionante tarea dogmática de proponer interpretaciones y soluciones respetuosas con los principios de la Política Criminal. Procede asi a efectuar interpretaciones y restricciones teleológicas que conducen a una aplicación sopesada y prudente de los preceptos y sus penas».

La monografía se estructura en introducción, tres partes (que se componen de siete capítulos) y sus respectivas conclusiones.

Desde la introducción, el autor da cuenta de la existencia de una categoría de delitos de dudosa legitimidad, la existencia de dichas normas obedece, entre otros factores, a «decisiones políticas erradas», si se me permite la expresión; y son erradas porque entran en conflicto con los principios básicos del Derecho Penal.

El trabajo empieza con una parte descriptiva, elaborando 
minuciosamente la recopilación de los preceptos que denomina preparatorios (o delitos de preparación), para después dar paso a la explicación del fenómeno de los delitos instrumentales; seguidamente, en la parte crítica, Cruz Palmera argumenta cuáles son los principales problemas de dichos preceptos, $\mathrm{y}$, acto seguido - en la parte constructiva- expone la tesis o la propuesta de solución al problema.

En la primera parte del trabajo, «El problema: Breve panorama del fenómeno de la preparación como delito", expone el fenómeno de la preparación delictiva desde otras perspectivas legislativas. Abordando asimismo, una clasificación de los delitos para luego agrupar un conjunto de cinco tipos penales que utiliza como modelo, presentando un balance crítico sobre la instrumentalidad como delito en el Código Penal español.

En la segunda parte, «La técnica de anticipar la intervención: Valoración crítica» profundiza en los principales problemas de esas normas penales, elaborando una confrontación de los delitos instrumentales con los principios básicos de Derecho Penal (legalidad, subsidiariedad, proporcionalidad, lesividad, presunción de inocencia, culpabilidad).

Así pues, al constatar la dudosa constitucionalidad de los delitos instrumentales, el autor asume la arriesgada tarea de revisar otras figuras de anticipación con el ánimo de encontrar razones que ayuden a comprender el fenómeno de la preparación delictiva. Y, para eso, expone una clasificación de instrumentos de anticipación en tres grados, anticipación dependiente, figuras de anticipación independiente o autónomas, y anticipación simultánea. En la anticipación dependiente revisa con cierta profundidad tanto la tentativa como los actos preparatorios punibles. En la anticipación autónoma se centra en el estudio de figuras como los delitos de tentativa, los delitos de peligro abstracto, y los delitos de participación. Finalmente, analiza el concurso medial o el delito medial como figura de anticipación simultánea.

En la tercera parte del trabajo, denominado «Construcción: Valoración de la legitimidad de la intervención y propuesta de solución», nos muestra una aportación desde la doctrina de la imputación objetiva. Resumidamente, intenta valorar cuándo y por qué la conducta instrumental puede desplegar un riesgo jurídicamente relevante lo que ocurre, - a juicio del autorcuando existe una «inserción estructural» y se demuestre objetivamente una "funcionalidad por reconfiguración».

De gran utilidad para la práctica, es el estudio que elabora a partir de un elevado conjunto de casos y supuestos prácticos que aparecen en el trabajo, especialmente en la segunda y tercera parte de la monografía.

Debe desatacarse, tanto la revisión como el análisis de no pocas instituciones de la Parte General en su trabajo; conjuntamente, resulta de interés que antiguos preceptos que habían sido derogados del Código Penal por vicios de inconstitucionalidad aparezcan nuevamente en el Código Penal español vigente. Esto es en resumen el aporte realizado por el trabajo del profesor Cruz Palmera.

Pese a la robustez y claridad en los conceptos, a nuestro juicio, el autor 
omite pronunciarse de fondo sobre una propuesta concreta para la disminución de las penas que tanto critica en el recorrido de las páginas. Consideramos que el lector echará de menos un estudio o una revisión minuciosa de la tentativa en figuras conflictivas como los delitos de preparación o delitos instrumentales, los cuales, a nuestro pesar, no fuero abordados por el autor.
En definitiva, y sin menoscabo de lo anterior, consideramos que el escrupuloso trabajo del profesor Cruz Palmera, expuesto tan ágilmente, nos proporciona un instrumento de reflexión y análisis sobre «la instrumentalidad delictiva» y nos proporciona interesantes reflexiones para la interpretación y aplicación de dichas normas penales.

José Nieves López ${ }^{1}$

Abogado

Universidad del Norte

${ }^{1} \mathrm{http}: / /$ scienti.colciencias.gov.co:8081/cvlac/visualizador/generarCurriculoCv. do?cod_rh $=0001379722$. 


\title{
Cruz Palmera, Roberto. Delitos instrumentales: Aspectos de polí- tica legislativa. BdeF, Buenos Aires/Montevideo, 2020, 327 pp., ISBN 978-9915-650-03-6.
}

\author{
http://dx.doi.org/10.18543/ed-68(2)-2020pp393-395
}

\section{Copyright}

Estudios de Deusto es una revista de acceso abierto, lo que significa que es de libre acceso en su integridad. Se permite su lectura, la búsqueda, descarga, distribución y reutilización legal en cualquier tipo de soporte sólo para fines no comerciales, sin la previa autorización del editor o el autor, siempre que la obra original sea debidamente citada y cualquier cambio en el original esté claramente indicado

Estudios de Deusto is an Open Access journal which means that it is free for full access, reading, search, download, distribution, and lawful reuse in any medium only for non-commercial purposes, without prior permission from the Publisher or the author; provided the original work is properly cited and any changes to the original are clearly indicated. 